\title{
Understanding creaminess
}

Frøst, Michael Bom; Janhøj, Thomas

Published in:

International Dairy Journal

DOI:

10.1016/j.idairyj.2007.02.007

Publication date:

2007

Document version

Early version, also known as pre-print

Citation for published version (APA):

Frøst, M. B., \& Janhøj, T. (2007). Understanding creaminess. International Dairy Journal, 17(11), 1298-1311. https://doi.org/10.1016/j.idairyj.2007.02.007 


\section{Review}

\section{Understanding creaminess}

Michael Bom Frøst*, Thomas Janhøj

Department of Food Science, Faculty of Life Sciences, University of Copenhagen, Rolighedsvej 30, DK-1958 Frederiksberg, Denmark

Published in International Dairy Journal 17(11) p.1298-1311

*Corresponding author. Tel.: +45 3528 3207; fax: +45 35283509

E-mail address: mbf@life.ku.dk (M. B. Frøst) 
Abstract

Our research has concerned creaminess in low fat dairy products of different types, covering the range from liquids (acidified milk drinks), over weak gels (vanilla yoghurts, plain stirred yoghurt) to semi-solids (cream cheese). We have studied both physical background for creaminess and sensory perception of creaminess. The intention has been to understand general aspects of creaminess that applies to the whole range of product categories studied, but also to explore differences between different types of dairy products. The goal has been to collect a coherent mass of knowledge linking different types of measurements with multivariate data analysis. The present paper presents an overview of our findings and discusses them, as well as drawing upon others' work to cover what we have not studied.

Keywords: Creaminess; Low fat dairy products; Sensory analysis; Rheology; Microstructure;

\section{Contents}

1. Introduction

2. Physical and chemical basis for creaminess

2.1. Relationships with physical and chemical properties - instrumental prediction of creaminess

3. Perception of creaminess

3.1. Correlations with other sensory properties

3.2. Individual differences in rating of creaminess

3.3. Integration of input from different sensory modalities

3.4. Neural correlates of multisensory stimuli

4. Conclusions

5. Future directions for creaminess research

Acknowledgements

References 


\section{Introduction}

Consumers increasingly demand products that possess positive nutritional qualities (e.g., a low fat or energy content), while simultaneously having appealing sensory properties. New and 'healthy' foods need to taste good to achieve success in the market place (Martens, Frøst, \& Martens, 2005). Developing and manufacturing these products is a continuing challenge for the dairy industry. As many as 75 to $90 \%$ of all new food products launched fail in the market (Buisson, 1995). Many of the first reduced-fat products to enter the market had poor and undesirable sensory properties, and low-fat products in general suffered from a bad image among consumers (Cardello, 1994). Regretfully consumers often perceive fat-reduced dairy products as less palatable than products of the same type, but with a higher fat content (Cardello, 1994; Tuorila, Cardello, \& Lesher, 1994). Although many successful low fat dairy products have been launched since the early days of low fat technology, the general impression is that consumer liking of low fat dairy products is still not equal to that of the full fat versions. Thus, technological challenges abound for the dairy industry, especially in mimicking the flavour and texture profiles of full-fat products.

'Creaminess' is a highly interesting and much debated topic. It is generally accepted that creaminess has an intrinsic positive hedonic ${ }^{1}$ component and is a key driver of sensory appeal. It has been demonstrated repeatedly in dairy products that consumers' hedonic response is strongly positively correlated to creaminess. This has been shown to be the case for both strawberry yoghurts (Ward, Koeferli, Schwegler, Schaeppi, \& Plemmons, 1999) and plain yoghurts (Folkenberg \& Martens, 2003). Furthermore it has been found that consumers' rated perception of creaminess in a broad range of liquid dairy products are strongly positively correlated to the same consumers

\footnotetext{
${ }^{1}$ hedonic - of or relating to pleasure. In wider use, mainly in psychology: of, pertaining to, or involving pleasurable or painful sensations or feelings, considered as affects, from Oxford English Dictionary.
} 
overall liking of the products (Richardson-Harman et al., 2000). In another product category containing dairy ingredients, vanilla pudding, the same relationships have been observed (Elmore, Heymann, Johnson, \& Hewett, 1999). Thus, naturally there is a high level of interest in understanding human perception of creaminess. Unfortunately, a high level of creaminess is often closely correlated with a high fat level. Technological solutions that reduce the fat content of dairy products, while still maintaining a desirable level of creaminess, are much wanted by the industry. The problems encountered by product development staff have been studied using qualitative methods (Parr, Knox, \& Hamilton, 2001). Problems with mouth feel/texture, flavour, changes to production process, shelf life as well as confusion with respect to which ingredients to use, were all mentioned as barriers to the development of low-fat dairy products.

Understanding creaminess can be approached from many angles, but requires a multidisciplinary effort to succeed. Over the years scientists have investigated creaminess from many different angles, posing and answering different scientific questions that can be classified as described below, even though it may prove impossible to completely separate the different research questions.

1. Physical and chemical basis for creaminess

a. Relationships with physical and chemical properties (instrumentally measured)

b. Effects of different ingredients (model systems and foods)

2. Sensory perception of creaminess (for consumers and trained sensory panellists)

a. Relationships between creaminess and other more simple sensory properties

b. Interactions between sensory modalities (vision, olfaction, gustation and touch)

c. The concept of creaminess

3. Human-food interactions

a. Effect of food breakdown

b. Oral processing and perception 
Over the past few years we have explored creaminess addressing questions of the two first

types. In our research we have covered low fat dairy products of different types, covering the range from liquids, over weak gels to semi-solids. The intention has been to understand general aspects of creaminess that apply to the whole range of product categories studied, but also to explore differences between different types of dairy products. The goal has been to collect a coherent mass of knowledge linking different types of measurements with multivariate data analysis. The present paper presents and overview of our findings, as well as drawing upon others' work to cover what we have not studied.

\section{Physical and chemical basis for creaminess}

The physical and chemical background for creaminess - before it becomes a sensory perception - is a necessary understanding for both material scientists and dairy product manufacturers to develop successful low fat dairy products.

Not surprisingly, creaminess is linked to milk fat globules in dairy products. Fat serves as the main solvent for many aroma compounds. Apart from this, fat, and especially milk fat, imparts a flavour of its own. Fat has a considerable impact on flavour release, causing a retardation of the release of flavour compounds from the food matrix; in low fat products flavour release tends to be faster. Using sensory time-intensity methods, (Frøst, Heymann, Bredie, Dijksterhuis, \& Martens, 2005) showed that for flavoured ice creams individual added flavour compounds were not affected similarly by changes in fat level.

Texturally, fat plays a role depending on whether it acts as an active filler or not. Milk fat globules act as structure breakers in gelled dairy products. Heat treatment of a homogenised milk base leads to incorporation of the fat phase into the protein matrix. In low-fat products this can be 
emulated by fat mimetics such as microparticulated whey proteins. However, Janhøj and Ipsen (2006) showed that these microparticles do not interact with the protein network, i.e., they do not act as active fillers. The functionality of microparticulated whey proteins is hence different from that of the milk fat globules they replace. Even so, microparticles still provide a very high creaminess in low fat plain yoghurts (Janhøj et al. 2006b). In $0.3 \%$ fat level addition of a partially microparticulated whey protein blend to a total protein level of $5.4 \%$ provided a higher creaminess than $3.5 \%$ fat yoghurt. Thus, the precise physical background for creaminess is still left somewhat unexplained. In a different interpretation of the functionality of fat it is suggested that the fat globules rotate relative to each other under shearing conditions, providing a fluidity of the mass of particles with a lubricating, 'ball-bearing' effect (Tolstoguzov, 2003).

At Wageningen Center for Food Science in Netherlands, de Wijk and co-workers have worked on the subject of creaminess since 1999, mainly using the Dutch vanilla custard product "vla" as a model (de Wijk, Terpstra, Janssen, \& Prinz, 2006). Vla is a semi-solid product, essentially consisting of milk gelled with starch. In their experiments creaminess was evaluated according to a consensual definition: "the range of sensations typically associated with fat content, such as full and sweet taste, compact, smooth, not rough, not dry, with a velvety (not oily) coating. Food disintegrates at a moderate rate". Fat levels were varied between $0-15 \%$. Added $\mathrm{SiO}_{2}$ particles (indeed, not a common food ingredient) in the size range 2-80 $\mu \mathrm{m}$ were found to be detrimental to creaminess (Engelen et al., 2005). Softer polystyrene particles had to be larger to give the same response (Engelen, van der Bilt, Schipper, \& Bosman, 2005), which could explain why commercial microparticulated whey protein at least are not detrimental to "Creaminess", despite having particle sizes in the range $\sim 0.1-3.0 \mu \mathrm{m}$. Another finding was that product and oral temperature did not affect "Creaminess" ratings, even though the sensory viscosity decreased. The decrease in viscosity was hypothesized to be compensated by other descriptors (Engelen et al., 
2003). Alpha-amylase and acarbose (an $\alpha$-amylase inhibitor) were found, respectively, to decrease and increase creamy mouth feel (de Wijk, Prinz, Engelen, \& Weenen, 2004). "Creaminess" was found to decrease somewhat with temperature in high-fat custards, and increase a little in low-fat custards. By using nose clips and flavours, the effect of olfactory cues and intranasal sensations on creamy mouth feel was confirmed (Weenen, Jellema, \& de Wijk, 2005).

Based on these findings on their findings a qualitative model for "Creaminess" perception was proposed (de Wijk et al., 2006). The model partitions the contributions to creaminess in two: bulk properties (rheological properties of the bolus) and surface properties. They suggest that during the breakdown of a food, internal fat globules surfaces and there enhance lubrication and release of fat-soluble flavours. The surfacing of fat is particularly important for low fat starch-based semisolid foods. The lower creaminess in low-fat custards was thus ascribed to a lack of lubrication, due to the lower fat content (de Wijk \& Prinz, 2005; de Wijk, van Gemert, Terpstra, \& Wilkinson, 2003a). Based on PLS models of "Creaminess" as a function of other sensory descriptors, the model was tentatively found to be generalisable to other semi-solids such as mayonnaises, sauces and yoghurts, even if some of the descriptors varied. One could argue that the proposed model disregards the microstructure of the products altogether; in particular the way that fat interacts with other components. In addition, it seems to fail to account for the functionality of fat mimetics such as microparticulated whey protein, unless the lubrication properties of these would be found to match those of fat, as has been suggested by others (Tolstoguzov, 2003). Evanescent wave spectroscopy has been suggested as a method to study deposition/lubrication phenomena of relevance to "Creaminess" (Malone, Appelqvist, \& Norton, 2003).

\subsection{Relationships with physical and chemical properties - instrumental prediction of creaminess}



understanding the underlying physical and chemical properties that give creamy products. The difficulty of describing "Creaminess" in purely rheological terms has long been acknowledged (Wood, 1974). A certain level of viscosity combined with a smooth mouth feel is considered a sine qua non condition for obtaining a creamy texture. Several other properties have been claimed to influence "Creaminess". In concentrated oil/water $(\mathrm{o} / \mathrm{w})$ emulsions such as creams, it has been suggested that a high density of evenly sized fat globules contribute to "Smoothness" perception, somewhat along the line of the previously mentioned 'ball-bearing' hypothesis. Daget and coworkers (Daget, Joerg, \& Bourne, 1988; Daget \& Joerg, 1991) ${ }^{2}$ linked creaminess in model dessert creams and model soups to rheological parameters. They could predict creaminess fairly well from viscosity and flow behaviour index with a quadratic relationship to perceived creaminess. However, in dessert creams (Daget et al., 1988) they found that for different fat levels, maximum creaminess was achieved at different viscosity levels. For model soups (Daget \& Joerg, 1991) they found that perceived creaminess changed according to the type of thickener they used. Both results indicate that the perceived creaminess depends on other factors than what is captured by rheological properties,

There has been much debate about which shear rate is prevalent in the mouth, not least because of the practical relevance (predictive purposes) of the issue. One of the most important results in this area has been the so-called ideal curve (Shama \& Sherman, 1973). According to this, the characteristic shear rate of a given food depends on its flow characteristics. Around the curve is a zone where shear stress has the best correlation with sensory properties. For yoghurt, the relevant shear rate should be around $50 \mathrm{~s}^{-1}$. This is merely an abstraction, as it is inconceivable that shear stress at about the same level should predominate throughout the oral cavity. The flow pattern

\footnotetext{
${ }^{2}$ Interestingly there is no mentioning in either of the two papers about neither the sensory methods they used, nor the subjects that evaluated the samples.
} 
during in the mouth has recently been modelled numerically (Mathmann et al., 2006), but so far only for Newtonian materials.

Kokini (1987), in his review of the physical basis for liquid food texture, suggested the following relationships: thickness - or perceived viscosity - is a function shear stress on the palate. Likewise the evaluation of smoothness involves frictional forces, so that smoothness is the reciprocal of the friction force. Perception of creaminess is a function of thickness and smoothness (for his precise formula, see below) both of which can be predicted from rheological properties.

In several of the studies on 'vla' an instrumental prediction of creaminess has been attempted. de Wijk, van Gemert, Terpstra, \& Wilkinson (2003b) found that even though they could accurately predict thickness from Brookfield $(\mathrm{r}=0.96)$ and Posthumus funnel $(\mathrm{r}=0.89)$, the relationship with Creamy/soft was much weaker. In predicting "Creaminess", rheological data alone (dynamic oscillation, shear viscometry, critical stress) could only account for at limited amount of information, with leave-one-out cross-validation correlation coefficient $\mathrm{Q}_{\mathrm{CV}}^{2}=0.48$ (Jellema, Janssen, Terpstra, de Wijk, \& Smilde, 2005); this was deemed reasonably good for high-throughput screening purposes. The idea would be to measure the rheological properties for a large number of samples, and predict "Creaminess" from these. Indeed, it would be interesting to see what the products would look like end after completing several cycles of "Creaminess" optimization using this methodology. Using more ingenious sensory methods (de Wijk, Prinz, \& Janssen, 2006), including friction as well as IR reflectance, turbidity and image edge detection on spat out bolus, much better predictions could be achieved ( $\mathrm{r}=0.96$ between actual and predicted "Creaminess"), but these methods are hardly useful for high-throughput screening.

Our experiments have shown also shown that creaminess can not always be predicted satisfactorily from rheological data alone. In plain stirred yoghurts (Janhøj, Petersen, Ipsen, \& Frøst, 2006c), we found that a large set of rheological data comprising shear viscometry, imperfect 
squeezing flow viscometry, Posthumus funnel and dynamic oscillation could only predict creaminess moderately $\left(\mathrm{R}^{2}=0.38\right)$. Other more straightforward sensory properties like oral viscosity could be predicted much better; remarkably, the best prediction of the latter was obtained by recording the weight of material exiting a so-called Posthumus funnel, and using this as the independent variable in PLS regression modelling.

By contrast, global image features extracted from confocal micrographs of the same yoghurt samples could predict as much as $\mathrm{R}^{2}=0.60$ of creaminess (Johansen, Janhøj, Laugesen, Ipsen, \& Frøst, 2006). This implies that the microstructure contains more information about creaminess than what is given through rheology. In other studies on cream cheese (Janhøj et al., 2006a) and acidified milk drinks (Janhøj, 2006; Janhøj, Frøst, \& Ipsen, 2006b), we obtained much better predictions of creaminess from rheological data $\left(\mathrm{R}^{2}=0.82\right.$ and 0.71$)$, but this was due to covariance with other underlying variables (sensory graininess and viscosity, respectively).

To study the relationships between sensory panel data and instrumental data, in one study we applied a regretfully under-utilized approach: combination of mixed-model ANOVA and measurement error methodology (Brockhoff, 2001). Where the traditional correlation coefficient assumes no measurement error, this approach allows separation between true correlations (related to an underlying structure) from the error. It makes it possible to find maximum correlations and confidence interval for correlations, and answer the question: "Considering the noise in the data, are the correlations as high as they can be?". Following this method, we found that squeeze flow and contraction flow perform similarly in predicting both creaminess as well as other key texture attributes.

Overall the results suggest that creaminess can be predicted with only moderate success by rheology, but the results from more cumbersome studies reflecting the dynamic processes during food breakdown and focusing on the human-food interaction show much more promise in 
prediction of creaminess. In a liquid (e.g., acidified milk drink: Janhøj, 2006; Janhøj et al., 2006b) and relatively solid dairy product categories (e.g., cream cheese; Janhøj et al., 2006a) the relationship between rheological properties and creaminess is more straightforward, and can thus be predicted quite precisely. In contrast to this, weak gels (e.g., plain yoghurt; Janhøj et al., 2006c) cannot be predicted well from rheological properties. Although some studies have shown that creaminess can be affected by changes in the aroma compounds (see below), we found no studies in the literature that have linked, e.g., gas chromatography with sensory analysis of products experimentally designed to vary in creaminess.

\section{Perception of creaminess}

Research on sensory perception of fat in several dairy products suggests it is closely connected to creaminess (Frøst, Dijksterhuis, \& Martens, 2001; Frøst, 2002; Mela, 1988; Mela, Langley, \& Martin, 1994; Mela \& Marshall, 1992). In liquid dairy products, fat takes the form of emulsified globules that are perceived as smooth and creamy (Mela, 1988). Some of our previous research (Frøst et al., 2001; Frøst, 2002) suggests that the sensory perception of fat and thus also creaminess involves several senses, at least including: vision, olfaction, gustation, and haptics (tactile sensation, i.e., texture and mouth feel). Accumulated evidence also suggests that "fat" may be considered a basic taste. However, this awaits further verification of the transduction mechanisms and characterisation of the effective stimuli. We suggest that creaminess is a metadescriptor, i.e., it is a compound property that is a result of a number of other properties. Creaminess is a multi-sensory experience and understanding the interaction between the different senses in perception in different food matrices will be beneficial for the development of low fat dairy products with appealing creaminess. 
Foods are not in equilibrium when eaten, and understanding of the dynamics of the perceptual processes as well as the food breakdown during consumption is central to disentangle the gamut of factors involved (Wilkinson, Dijksterhuis, \& Minekus, 2000). Texture and mouth feel (oral haptics) are both active senses - it is only during motion that we can fully perceive them (de Wijk, Engelen, \& Prinz, 2003; Lucas, Prinz, Agrawal, \& Bruce, 2002). We need to understand the food breakdown during consumption, as texture properties are important for "Creaminess". (Hutchings \& Lillford, 1988) suggested an approach that emphasises that texture perception is a dynamic sensory monitoring of changes of the food by the processes taking place in the mouth. They suggest a general three dimensional model applicable to all foods with "Degree of Structure", "'Degree of lubrication", and "Time" as its axes. As each food is changed in the mouth, it describes its own "Breakdown Path", throughout the three dimensions. This approach should be seen as a start point of a general hypothesis for the physics and psychophysics of mastication.

Szczesniak in an overview paper discussing texture research (Szczesniak, 2002), states that texture is a sensory property. As such it is only a human being that can perceive and describe it. Instrumental measurements can only detect and quantify certain physical parameters which then need to be interpreted in terms of sensory perception (Szczesniak, 2002). For liquids and semisolids she classifies creaminess as a "feel on soft tissue surface" property together with smoothness and pulpy. In concentrated o/w emulsions such as creams, it has been suggested that a high density of evenly sized fat globules contribute to "Smoothness" perception, somewhat along the line of the previously mentioned 'ball-bearing' hypothesis. Richardson, Booth, and Stanley (1993) have theorised that small evenly sized fat particles (obtained by e.g., homogenisation) make an essential contribution to perception of cream-like texture. However, their results showed that homogenisation of milk only had an effect on perceived creaminess when the milk was also thickened to the viscosity of double cream $(47.5 \%$ fat $)$. The effects of fat globule size and distribution on creaminess 
in a milk-relevant viscosity range thus lacked examination. Frøst et al. (2001) examined it in a more realistic milk products series, and found no effect of homogenisation alone on neither creaminess, nor fat perception. Likewise, later studies have also not been able to demonstrate an effect of oil droplet size on "Creaminess", "Thickness" or taste (Akhtar, Stenzel, Murray, \& Dickinson, 2005). Emulsifier type has been shown to influence creaminess of o/w emulsions (Moore, Langley, Wilde, Fillery-Travis, \& Mela, 1998).

An early attempt at quantifying "Creaminess" is condensed in the formula (Kokini \& Cussler, 1983; Kokini, 1987):

$$
\text { Creaminess }=\text { Thickness }^{0.54} \text { Smoothness }^{0.84}
$$

Here "Creaminess"is modelled by two sensory variables, namely "Thickness" and "Smoothness". There is no direct mention of rheological methods, but is suggested that "Creaminess" can be predicted from rheological and frictional properties, since "Thickness" and "Smoothness" can be predicted from these physical properties. The derivation of this expression is interesting, and says a great deal about the way sensory studies were performed the 1970s and 80s. The first part of the study was to generate vocabularies of texture terms for a series of fluid and semi-solid ranging from apple juice to butter, subsequently eliminate redundant terms, and finally use magnitude estimation to quantify the selected variables and fit the model. Sensory terms were collated by the untrained panellists individually, as they were told to list as many words as possible that described the texture of the samples. Subsequently the 15 most mentioned words were applied as descriptors in magnitude estimation. In magnitude estimation the panellists are told to score the intensities of a given attribute relative to that of a standard, i.e., a ratio scale is used. Averaged attribute scores were then regressed one by one on the remaining descriptors using multiple linear regressions, yielding a correlation matrix, from which redundant terms were identified. 
As has been pointed out, this approach would not have been used today (Elmore et al.,

1999), where descriptive analysis (and the corresponding multivariate data analysis) is considered state of the art (Lawless \& Heymann, 1998). And, by excluding some descriptors that are clearly perceivable, we risk bias by the dumping effect. The dumping effect may occur when subjects are not allowed to rate all present sensations. Then the panellists may "dump" a sensation (e.g., vanilla) to an inappropriate scale (e.g., sweetness) and thereby erroneously change the rating of this property. Our approach has been to collect full descriptive analysis of the samples in each experimental set. Table 1 lists all sensory descriptors used in our four experiments. Table 2 lists the main differences between our sensory methods, and those of Kokini and co-workers (Kokini \& Cussler, 1983; Kokini, Poole, Mason, Miller, \& Stier, 1984; Kokini, 1987).

With our most coveted descriptor "Creaminess" we used a very different approach than with the rest. The very use of the descriptor was imposed by the panel leader. No consensus on the use of the term "Creaminess" was sought between the panellists, similar to the procedure of Kilcast and Clegg (2002). Indeed, the panellists were instructed to use their own idiosyncratic concept of "Creaminess". No reference material was provided. All three items violate the principles of descriptive analysis to varying degrees. Moreover, the very concept of asking a panellist to assign a score of a complex descriptor such as "Creaminess" is actually a violation of the simple psychophysical model underlying all sensory science (Lawless \& Heymann, 1998). We chose this approach to study the perception of "Creaminess". Had we carefully defined the descriptor to the panellists, they would have merely returned this definition to us, and we would have learned nothing new from it. Allowing idiosyncratic definition of creaminess gave us the opportunity to explore differences in creaminess ratings among the panellists. 


\section{1. $\quad$ Correlations with other sensory properties}

As previously mentioned, Kokini and co-workers suggested that "Creaminess" is related to smoothness and viscosity (Kokini, Kadane, \& Cussler, 1977; Kokini \& Cussler, 1983; Kokini et al., 1984; Kokini, 1987). However, in their studies, panellists were instructed to only describe the texture of the samples, so contributions from other sensory modalities were obviously not discovered. Other studies, using descriptive sensory analysis have shown contributions from aroma/flavour and taste sensations. In vanilla pudding (Elmore et al., 1999), showed that besides from texture properties dairy and sweet flavour also contributed to consumers' liking of creaminess. Kora, Latrille, Souchon, and Martin (2003) showed that addition of flavouring agent decreased thickness, also indicating some texture-flavour interactions in low fat flavoured yoghurts.

Over the course of the project we have performed four different descriptive analyses, encompassing both liquid (acidified milk drinks), weak gels (plain yoghurts, vanilla yoghurts), and semi-solid to solid (cream cheese) dairy products. Table 3 lists correlation coefficient between each individual descriptor and creaminess for all experiments. From this it is clear that other sensory properties more than only texture properties relate to creaminess. Some visual properties are closely linked to the structure of the sample and thus co-vary with some texture properties (e.g., glossy, grainy, visual viscosity). We have used structure-related correlations to predict creaminess fairly well from surface images of yoghurts and cream cheese (Johansen, Laugesen, Janhøj, Ipsen, \& Frøst, 2006). Among the texture properties it is apparent that smoothness is central for creaminess, with a positive correlation in all four dairy product categories. But also viscosity and fatty after mouth feel are important properties. In contrast, other structure properties like presence of grains, chalkiness, stickiness and a dry after mouth feel is detrimental to creaminess. Astringency elicits an interesting behaviour: in a liquid system (acidified milk drinks) it is positively correlated to creaminess, but in the other systems it is negatively correlated. In the specific acidified milk drinks 
astringency is related to a high milk solid non-fat level. These samples were also the ones with a higher viscosity, cream flavour and fatty after mouth feel. So the negative effect of astringency on creaminess may be overruled by the other properties. Other sensory properties like aroma, flavour, and taste are not linked to structure in the same rigid fashion. In all four cases a positive correlation between cream flavour and creaminess is found. So deliberately manipulating the level of cream flavour, can affect the perceived creaminess. This has previously been shown in milk (Frøst et al., 2001), but failed to have an effect in cream cheese (Frøst, 2002). By attending to details in the individual product categories differences will be revealed.

Our study of acidified milk drinks (Janhøj et al., 2006b), showed that although smoothness and creaminess is correlated, the relationship is not straightforward. The interrelationships among different descriptors showed that our highly interesting descriptor "Creaminess" is well correlated to a number of descriptors encompassing both, appearance, aroma, taste, flavour and texture (refer to Table 3). In contrast, smoothness is only moderately positively correlated to "Creaminess" (correlation coefficient $=0.238$, Table 3). However, as Fig. 1 shows, it is evident that the difference in milk solids non-fat yields two markedly different types of relationships. We suggest two plausible reasons for these differences: 1) it stems from a higher intensity in dairy flavours with a positive contribution to "Creaminess", here: "Buttermilk" and "Cream flavour", combined with a lower intensity in dairy flavours that decrease Creaminess, here: "Boiled milk flavour" for the high milk solids nonfat samples. 2) At a higher level of "Viscosity", its contribution to "Creaminess" overrules that of "Smoothness", so even samples with low "Smoothness" can still possess a very high "Creaminess".

We studied vanilla yoghurts (Frøst, 2006), systematically varying both texture (different levels of total protein adjusted with a microparticulated whey protein blend), taste (sugar level) and vanilla intensity (flavour levels). Here we also found that viscosity and smoothness are positively 
correlated to "Creaminess" (refer to Table 3), but that sweetness and flavour notes like cream, vanilla, coconut and caramel also contribute in a positive manner. Similarly, in plain yoghurts (Janhøj et al., 2006c) it appears that although the major contribution to "Creaminess" in yoghurts is related to texture and mouth-feel descriptors, a number of flavour descriptors are also involved (refer to Table 3). Based on the broad range of sensory properties of the samples, we feel confident in making a general conclusion about "Creaminess" in stirred plain yoghurts. A stirred plain yoghurt with high "Creaminess" is characterized by a relatively high, but not too high, viscosity. It must possess a smooth mouth feel, and fatty after mouth feel. The yoghurts with high "Creaminess" ratings are also high in intensity of fat-related flavors, like cream, and butter, and they are sweeter than those with less "Creaminess". Lastly, in cream cheese (Janhøj et al., 2006a) we found that several key sensory attributes are strongly correlated. The positive correlation between "Creaminess" and key textural attributes such as smoothness and meltdown rate is high. But also glossy and some flavour notes like cream and butter show clear positive correlations with creaminess (refer to Table 3).

\subsection{Individual differences in rating of creaminess}

Individual differences in many types of perception are a fact. Some can be linked to exposure and culture, others to genetic factors. A few studies have investigated how background or genetics affect creaminess perception. PROP-taster status has been suggested as a reason for individual differences. PROP (6-n-propylthiouracil) is a bitter tasting compound, the perception of which is genetically determined. Individuals can be grouped as non-tasters, medium tasters and super-tasters based upon their sensitivity to PROP (Bartoshuk, Duffy, \& Miller, 1994). Tasters (medium and super-tasters) are more sensitive to a number of stimuli - among them fat (Bartoshuk, 
2000). Super-tasters have more taste buds in their mouth. They are innervated by trigeminal and

417 other nerve fibers, which may produce a greater somatosensory sensation on the tongue. PROP418 taster status and creaminess perception have been investigated in semi-trained subjects (Kirkmeyer 419 \& Tepper, 2003b) and has later been extended to consumers (Kirkmeyer \& Tepper, 2005). They 420 found that super-tasters overall used a more complex vocabulary to describe creaminess in dairy products and they relied more heavily on dairy flavour and texture attributes in their evaluation. So even though the overall impression of creaminess was similar for non-tasters and super-tasters, the sensory cues the two groups used to evaluate creaminess were different.

Since we allowed trained sensory panellists to use their idiosyncratic definitions of creaminess, we could investigate differences among them in creaminess-ratings. Significant individual differences were observed among the panellists in the plain yoghurt experiment (Frøst, Janhøj, \& Martens, 2004; Frøst \& Janhøj, 2006). A subsequent detailed analysis of all four experiments showed that some panellists emphasise flavour contributions more than others, in accordance with the findings of Kirkmeyer \& Tepper (2003a). In our vanilla yoghurt study (Frøst, 2006), we observed a puzzling difference between the sensory panel and untrained subjects. The trained panel showed a slight positive effect of vanilla flavour concentration on creaminess, while the untrained subjects showed a decrease in creaminess ratings at the high vanilla flavour concentration. The reason for this difference can be that the ordinary consumer perceives food in a synthetic manner - i.e., perceiving the totality of the food, whereas the perception of the sensory panellist in the sensory booth is extremely analytical, paying attention to all details separately. We suggest that the different modes of perception - synthetic and analytical - can affect the rating in experimental situations.

Currently only one study has examined cross-cultural differences in creaminess perception. As part of a study on differences in perception of sweetness and liking between Australians and 
Japanese, Prescott et al. (1997) also evaluated creaminess in ice creams. Results showed that, in ice

cream with lower sweetness, Japanese rated creaminess higher than Australians did. In a very recent experiment cross-cultural differences in perception of creaminess were investigated in Danish and Korean students, chosen to represent populations with very different food habits. We examined creaminess and hedonic perception in a set of six long-life acidified milk drinks, using 384 subjects equally divided between Seoul and Copenhagen, balanced over gender. The results showed cultural differences in creaminess ratings (Frøst, Kim, Kim, \& Prescott, 2006). These differences indicate that creaminess may not be universal but to some extent it is a learned percept, reflecting the foods we have been exposed to.

\subsection{Integration of input from different sensory modalities}

It is questionable if creaminess perception depends on exactly the same factors in all types of dairy products. Comparisons of sensory perception of fat in liquids and solid dairy products show inferior estimations and discrimination of fat levels in solid foods (Drewnowski, Shrager, Lipsky, Stellar, \& Greenwood, 1989). Similarly, ratings of creaminess in the same foods provided better discrimination in liquids than in solids. It indicates markedly different sensory pathways for fat and creaminess in different food matrices. The physical state of the food system (liquid, weak gel, semisolid to solid foods) affects the importance of different senses in perception of creaminess, as outlined above.

Approaches to study sensory interactions can be to exclude of one or more of the senses, then observe the effect on the perception - in this case perceived creaminess. Most often vision and olfaction is excluded. Visual stimulation can easily be blocked by preventing visual access to the food, e.g., by serving it in closed containers with a straw, serving it under lowlight conditions, or 
more cumbersome - blindfolding subjects. Olfaction can be excluded by blocking the nose either with a nose clip, or simply asking subjects to pinch the nose during the experiment. In some studies taste has been excluded by anaesthesia (Todrank \& Bartoshuk, 1991; Lehman, Bartoshuk, Catalanotto, Kveton, \& Lowlicht, 1995). However, for perception under normal food and beverage consumption circumstances the most relevant senses to exclude are vision (similar to drinking from a closed container), and to some degree olfaction (having a cold, and the orthonasal lack of aroma/smell when drinking through a straw). By adding a flavour substance and using nose clips, the effect of olfactory cues and the intranasal sensation on creamy mouth feel was confirmed in vla (Weenen et al., 2005). With similar approaches Kora et al. (2003) and Saint-Eve, Paci Kora, and Martin (2004) have studied texture-flavour interactions in yoghurts, and found effects on texture perception (smoothness and thickness) of the complexity of the flavouring agent. In contrast to this, we found that even though input from different senses is integrated in the creaminess percept, it is remarkably robust to the absence of the visual and olfactory input. Our results, with 40 untrained subjects, show that the creaminess ratings for nine sensory different vanilla-flavoured yoghurts remain unchanged when both visual and olfactory inputs are excluded. This indicates that mouth feel and taste provides sufficient sensory input that allows the absent input to be reliably predicted and thus give the full percept of creaminess.

\subsection{Neural correlates of multisensory stimuli}

The cortical representation of food texture, gustatory and olfactory perception shows some degree of convergence in specific areas in the orbitofrontal cortex, where single-neuron recording on primates has shown that some neurons respond to specific patterns of combinations of sensory inputs (Rolls, 2004). Responses to sensory properties of fat show that some converge from taste, and others to odour representations (Rolls, Critchley, Browning, Hernadi, \& Lenard, 1999). 
Interestingly, some populations of neurons in the orbitofrontal cortex in macaque monkeys have been found to respond to viscosity stimuli (carboxymethyl cellulose solutions of different viscosities), while others respond specifically to gritty texture (in the form of suspended microspheres). Some neurons respond unimodally to texture, while others also receive taste input (Rolls, Verhagen, \& Kadohisa, 2003). The results provide some initial evidence about the information channels that is used to represent the texture and flavour of food. The orbitofrontal cortex is also an important region of the brain with respect to representation of the reward value of sensory inputs (Kringelbach, O'Doherty, Rolls, \& Andrews, 2003; Kringelbach, 2004; Rolls, 2004). This indicates that the cortical representation of complex sensory inputs with high reward value, e.g., a food product with high creaminess, may converge in this region. The neurocognitive correlates of sensory integration of multimodal stimuli like foods are still largely unmapped (Verhagen \& Engelen, 2006). Many interactions between sensory modalities can be observed, but the neural bases for the multisensory integration are currently not understood well. Just recently there is an emergence of neuroscientific models providing a framework for further exploration of this field (Verhagen \& Engelen, 2006). The coupling of multisensory integration with our percept of reward and subjective pleasantness may provide very useful cues for to understand control of food intake and appetite (Rolls, 2005).

\section{Conclusions}

Taken together the findings in all investigated types of dairy products support the contention that texture properties plays an important role for the creaminess. Our findings suggest that texture properties are most decisive for creaminess in liquid (milk drinks) and semi-solid (cream cheese) products, but that flavour properties (aromas with positive connotations and sweetness) contribute 
more in weak gels (stirred yoghurts). The sensory properties that correlate most with creaminess irrespective of product type are: smoothness, fatty after mouth feel and cream flavour. As with many other sensory perceptions, our results show that there are significant individual, as well as cultural differences. The differences in creaminess ratings we observed between untrained subjects and a sensory panel may be an effect of a general difference between synthetic and analytical perception.

Our results, viewed together with results from de Wijk et al. (2006) support the notion that instrumental predictions of creaminess need to take into account the dynamic (i.e., time-dependent) aspect of food breakdown. On the data analytical side, we find that a model-free, soft-modelling approach to psychorheology, in which raw data is linked to sensory scores using multivariate techniques, in general outperforms the prevalent uni-variate methods where sensory data is regressed on more or less physically meaningful parameters extracted, e.g., from flow or compression curves.

\section{Future directions for creaminess research}

We suggest several lines of research for the future. Studies on the effect of our physiological states - hungry or full - is an interesting path to follow. The question is: does our desire for "Creaminess" depend on our need for nutrients at that time-point? And further - it is well-known that during consumption of a food, the sensory specific satiety changes (Rolls, Rolls, Rowe, \& Sweeney, 1981). Eating a food to satisfaction decreases the perceived pleasantness of this food but knowledge about how it affects perceived "Creaminess" is lacking. Studies examining this will provide some insight into whether "Creaminess" is a neutral sensory property, or a positive stimulus 
reward - an affective learned association. It may well be that it creaminess is both a sensory property, but simultaneously a hedonic experience.

Mastering the fundamentals of the formation and control of oral graininess in low-fat acid milk gel products will enable the dairy industry to develop products with a higher acceptability for the consumer. In the fresh cheese segment, in particular, there are several process parameters to play manipulate ( $\mathrm{pH}$, salt, etc.). With regards to microparticulated protein, there will no doubt be much activity in both fundamental research and more application oriented work in the time to come. There is ample room for developing micro-particles with properties (particle size distribution, surface reactivity) tailored to specific applications. A better mechanistic understanding of how these ingredients interact with food matrices, and its relevance to the sensory perception is still much needed.

For instrumental prediction of creaminess, we suggest development of methods that are a combination of static and dynamic measurements. They should also be linked close to physical properties, so that the precise mechanisms of fat and its mimetics can be elucidated. In vitro, imitative methods would be of great use to the dairy industry as a means of screening product formulation, but a much higher degree of sophistication than that of the old instrumental Texture Profile Analysis method is necessary, both on the hardware side and the data analytical side. The interactions between food and palate are crucial for new insight in this area. We suggest studies of surface adhesion and the attenuation of forces on the palate by microlayer of food adhered to the palate.

\section{Acknowledgments}


560 Production Sciences (M.B. Frøst) and the Danish Dairy Research Foundation - Danish Dairy Board 561 (T. Janhøj). Collaborators from Arla Foods Ingredients, Nr. Vium Denmark (yoghurts); Arla Food 562 Innovation, Brabrand Denmark (cream cheeses); Symrise, Holzminden Germany (vanilla flavour 563 for yoghurts); and CP Kelco, Lille Skensved Denmark (acidified milk drinks) are thanked for 564 producing and donating products for experiments, as well as specific products knowledge during the 565 planning and performance of the studies. The technical staff from the sensory panel, Judith 566 Henning, Rikke Jensen, Maja Nerup Jensen and Lisbeth Pii Nielsen are thanked for assistance with 567 sensory tests.

\section{References}

Akhtar, M., Stenzel, J., Murray, B. S., \& Dickinson, E. (2005). Factors affecting the perception of creaminess of oil-in-water emulsions. Food Hydrocolloids, 19, 521-526.

Bartoshuk, L. M. (2000). Comparing sensory experiences across individuals: recent psychophysical advances illuminate genetic variation in taste perception. Chemical Senses, 25, 447-460.

Bartoshuk, L. M., Duffy, V. B., \& Miller, I. J. (1994). PTC/PROP tasting: anatomy, psychophysics and sex effects. Physiology and Behavior 56, 1165-1171.

Brockhoff, P. B. (2001). Sensory profile average data: combining mixed model ANOVA with measurement error methodology. Food Quality and Preference, 12, 413-426.

Buisson, D. (1995). Developing new products for the consumer. In D. Marshall (Ed.), Food choice and the consumer (pp.182-215). Glasgow, UK: Blackie Academic. 
Cardello, A. V. (1994). Consumer expectations and their role in food acceptance. In H.J.H. Macfie \& D.M.H. Thomson (Eds.), Meaurement of food preferences (pp. 223-297). London, UK: Blackie Academic and Professional.

Daget, N. \& Joerg, M. (1991). Creamy Perception 2. in Model Soups. Journal of Texture Studies, 22, 169-189.

Daget, N., Joerg, M., \& Bourne, M. (1988). Creamy perception 1. In model dessert creams. Journal of Texture Studies, 18, 367-388.

de Wijk, R. A. \& Prinz, J. F. (2005). The role of friction in perceived oral texture. Food Quality and Preference, 16, 121-129.

de Wijk, R. A., van Gemert, L. J., Terpstra, M. E. J., \& Wilkinson, C. L. (2003a). Texture of semisolids; sensory and instrumental measurements on vanilla custard desserts. Food Quality and Preference, 14, 305-317.

de Wijk, R. A., Engelen, L., \& Prinz, J. F. (2003). The role of intra-oral manipulation in the perception of sensory attributes. Appetite, 40, 1-7.

de Wijk, R. A., Prinz, J. F., \& Janssen, A. M. (2006). Explaining perceived oral texture of starchbased custard desserts from standard and novel instrumental tests. Food Hydrocolloids, 20, 24-34.

de Wijk, R. A., Prinz, J. F., Engelen, L., \& Weenen, H. (2004). The role of alpha-amylase in the perception of oral texture and flavour in custards. Physiology and Behavior, 83, 81-91.

de Wijk, R. A., Terpstra, M. E. J., Janssen, A. M., \& Prinz, J. F. (2006). Perceived creaminess of semi-solid foods. Trends in Food Science and Technology, 17, 412-422. 
de Wijk, R. A., van Gemert, L. J., Terpstra, M. E. J., \& Wilkinson, C. L. (2003b). Texture of semisolids; sensory and instrumental measurements on vanilla custard desserts. Food Quality and Preference, 14, 305-317.

Drewnowski, A., Shrager, E. E., Lipsky, C., Stellar, E., \& Greenwood, M. R. C. (1989). Sugar and fat: Sensory and hedonic evaluation of liquid and solid foods. Physiology and Behavior, 45, $177-183$.

Elmore, J. R., Heymann, H., Johnson, J., \& Hewett, J. E. (1999). Preference mapping: relating acceptance of 'creaminess' to a descriptive sensory map of a semi-solid. Food Quality and Preference, 10, 465-475.

Engelen, L., de Wijk, R. A., Prinz, J. F., Janssen, A. M., Weenen, H., \& Bosman, F. (2003). The effect of oral and product temperature on the perception of flavor and texture attributes of semi-solids. Appetite, 41, 273-281.

Engelen, L., de Wijk, R. A., van der Bilt, A., Prinz, J. F., Janssen, A. M., \& Bosman, F. (2005). Relating particles and texture perception. Physiology and Behavior, 86, 111-117.

Engelen, L., van der Bilt, A., Schipper, M., \& Bosman, F. (2005). Oral size perception of particles: effect of size, type, viscosity and method. Journal of Texture Studies, 36, 373-386.

Folkenberg, D. M. \& Martens, M. (2003). Sensory properties of low fat yoghurts. Part B: Hedonic evaluations of plain yoghurts by consumers correlated to fat content, sensory profile and consumer attitudes. Milchwissenschaft-Milk Science International, 58, 154-157. 
Frøst, M. B. (2002). The influence of fat content on sensory properties and consumer perception of dairy products. PhD-thesis The Royal Veterinary and Agricultural University, Centre for Advanced Food Studies, Department of Dairy and Food Science, Aarhus, Denmark.

Frøst, M. B., Dijksterhuis, G. B., \& Martens, M. (2001). Sensory perception of fat in milk. Food Quality and Preference, 12, 327-336.

Frøst, M. B., Heymann, H., Bredie, W. L. P., Dijksterhuis, G. B., \& Martens, M. (2005). Sensory measurement of dynamic flavour intensity in ice cream with different fat levels and flavourings. Food Quality and Preference, 16, 305-314.

Frøst, M. B. \& Janhøj, T. (2006). Multi-way analysis of individual differences in perception of creaminess within a sensory panel. Food Quality and Preference, submitted.

Frøst, M. B., Janhøj, T., \& Martens, M. (2004). Multi-way analysis of individual differences in perception of creaminess within a sensory panel. The Seventh Sensometrics Meeting [Online]. Available: http://www.sensometric.org/pages/lectures.htm

Frøst, M. B. (2006). Liking and exposure: First, second and tenth time around. Physiology and Behavior, 89, 47-52.

Frøst, M. B., Kim H.S., Kim, K. O., \& Prescott, J. (2006). Cross-cultural differences in creaminess and hedonic perception between Korean and Danish college students. Manuscript in preparation.

Hutchings, J. B. \& Lillford, P. J. (1988). The perception of food texture - the philosophy of the breakdown path. Journal of Texture Studies, 19, 103-115. 
IDF (1997). Sensory evaluation of dairy products by scoring - Reference Method IDF standard 99C. Brussels, Belgium: International Dairy Federation.

ISO (1993). Sensory analysis - Methodology - general guidance for the selection, training and monitoring of assessors. International Standard 8586-1. Geneva, Switzerland: International Organisation for Standardisation.

Janhøj, T. (2006). Microstructure and sensory perception of low-fat, semi-solid dairy products. PhD-thesis Department of Food Science - LMC, Royal Veterinary and Agricultural University, Aarhus, Denmark.

Janhøj, T., Frøst, M. B., Andersen, C. M., Viereck, N., Ipsen, R. H., \& Edrud, S. (2006a). Sensory, rheological and spectroscopic characterization of low-fat and non-fat cream cheese. In P. Fischer, P. Erni, \& E. J. Windhab (Eds.), Proceedings from the 4th International Symposium on Food Rheology and Structure, Zürich, Switzerland (pp. 383-387).

Janhøj, T., Frøst, M. B., \& Ipsen, R. (2006b). Sensory and rheological characterisation og acidified milk drinks. Submitted to Food Hydrocolloids.

Janhøj, T. \& Ipsen, R. H. (2006). Effect of pre-heat treatment on the functionality of microparticulated whey protein in acid milk gels. Milchwissenschaft, 61, 131-134.

Janhøj, T., Petersen, C. B., Ipsen, R., \& Frøst, M. B. (2006c). Sensory and rheological characterization of low-fat stirred yoghurt. Journal of Texture Studies, 37, 276-299.

Jellema, R. H., Janssen, A. M., Terpstra, M. E. J., de Wijk, R. A., \& Smilde, A. K. (2005). Relating the sensory sensation 'creamy mouthfeel' in custards to rheological measurements. Journal of Chemometrics, 19, 191-200. 
Johansen, S. M. B., Janhøj, T., Laugesen, J. L., Ipsen, R., \& Frøst, M. B. (2006). Prediction of sensory properties of semi-solid dairy products from confocal laser scanning micrographs using global feature extraction and multivariate regression techniques. Manuscript in preparation.

Johansen, S. M. B., Laugesen, J. L., Janhøj, T., Ipsen, R. H., \& Frøst, M. B. Prediction of sensory properties of low-fat yoghurt and cream cheese from surface images. Submitted to Food Quality and Preference.

Kilcast, D. \& Clegg, S. (2002). Sensory perception of creaminess and its relationship with food structure. Food Quality and Preference, 13, 609-623.

Kirkmeyer, S. V. \& Tepper, B. J. (2003a). Understanding creaminess perception of dairy products using free-choice profiling and genetic responsivity to 6-n-propylthiouracil. Chemical Senses, 28, 527-536.

Kirkmeyer, S. V. \& Tepper, B. J. (2003b). Understanding creaminess perception of dairy products using free-choice profiling and genetic responsivity to 6-n-propylthiouracil. Chemical Senses, 28, 527-536.

Kirkmeyer, S. V. \& Tepper, B. J. (2005). Consumer reactions to creaminess and genetic sensitivity to 6-n-propylthiouracil: A multidimensional study. Food Quality and Preference, 16, 545556.

Kokini, J. L. \& Cussler, E. L. (1983). Predicting the Texture of Liquid and Melting Semi-Solid Foods. Journal of Food Science, 48, 1221-1225. 
Kokini, J. L., Kadane, J. B., \& Cussler, E. L. (1977). Liquid texture perceived in mouth. Journal of Texture Studies, 8, 195-218.

Kokini, J. L., Poole, M., Mason, P., Miller, S., \& Stier, E. F. (1984). Identification of key textural attributes of fluid and semi-solid foods using regression-analysis. Journal of Food Science, 49, 47-51.

Kokini, J. L. (1987). The physical basis of liquid food texture and texture-taste interactions. Journal of Food Engineering, 6, 51-81.

Kora, E. P., Latrille, E., Souchon, I., \& Martin, N. (2003). Texture-flavor interactions in low fat stirred yogurt: How mechanical treatment, thickener concentration and aroma concentration affect perceived texture and flavor. Journal of Sensory Studies, 18, 367-390.

Kringelbach, M. L. (2004). Food for thought: Hedonic experience beyond homeostasis in the human brain. Neuroscience, 126, 807-819.

Kringelbach, M. L., O'Doherty, J., Rolls, E. T., \& Andrews, C. (2003). Activation of the human orbitofrontal cortex to a liquid food stimulus is correlated with its subjective pleasantness. Cerebral Cortex, 13, 1064-1071.

Lawless, H. T. \& Heymann, H. (1998). Sensory Evaluation of Foods: Principles and Practices. New York, USA: Chapman and Hall.

Lehman, C. D., Bartoshuk, L. M., Catalanotto, F. C., Kveton, J. F., \& Lowlicht, R. A. (1995). Effect of anesthesia of the chorda tympani nerve on taste perception in humans. Physiology and Behavior, 57, 943-951. 
Lucas, P. W., Prinz, J. F., Agrawal, K. R., \& Bruce, I. C. (2002). Food physics and oral physiology. Food Quality and Preference, 13, 203-213.

Malone, M. E., Appelqvist, I. A. M., \& Norton, I. T. (2003). Oral behaviour of food hydrocolloids and emulsions. Part 1. Lubrication and deposition considerations. Food Hydrocolloids, 17, 763-773.

Martens, M., Frøst, M. B., \& Martens, H. (2005). Consumer attitudes to health and pleasure survey data studied by PLSR. In T. Aluja, J. Casanovas, V. Espositi Vinzi, A. Morineau, \& M. Tenenhaus (Eds.), Proceedings of the PLS'05 International Symposium, Barcelona, Spain (pp. 431-437).

Mathmann, K., Kowalczyk, W., Petermeier, H., Eberhard, M., Baars, A., \& Delgado, A. (2006). The impact of rheological properties on mouthfeel caused by food. In P. Fischer, P. Erni, \& E. J. Windhab (Eds.), Proceedings from the 4th International Symposium on Food Rheology and Structure, Zürich, Switzerland (pp. 459-463).

Mela, D. J. (1988). Sensory assessment of fat content in fluid dairy products. Appetite, 10, 37-44.

Mela, D. J., Langley, K. R., \& Martin, A. (1994). Sensory Assessment of Fat-Content - Effect of Emulsion and Subject Characteristics. Appetite, 22, 67-81.

Mela, D. J. \& Marshall, R. J. (1992). Sensory properties and perceptions of fats. In D.J. Mela (Ed.), Dietary fats - determinants of preference, selection and consumption (pp. 43-57). London, UK: Elsevier. 
Moore, P. B., Langley, K., Wilde, P. J., Fillery-Travis, A., \& Mela, D. J. (1998). Effect of emulsifier type on sensory properties of oil-in-water emulsions. Journal of the Science of Food and Agriculture, 76, 469-476.

Parr, H. J., Knox, B., \& Hamilton, J. A. (2001). Problems and pitfalls in the development and marketing of reduced-fat foods. Leatherhead Food RA Food Industry Journal, 4, 50-60.

Prescott, J., Bell, G. A., Gillmore, R., Yoshida, M., O'Sullivan, M., Korac, S. et al. (1997). Crosscultural comparisons of Japanese and Australian responses to manipulations of sweetness in foods. Food Quality and Preference, 8, 45-55.

Richardson, N. J., Booth, D. A., \& Stanley, N. L. (1993). Effect of homogenization and fat content on oral perception of low and high viscosity model creams. Journal of Sensory Studies, 8, $133-143$.

Richardson-Harman, N. J., Stevens, R., Walker, S., Gamble, J., Miller, M., Wong, M. et al. (2000). Mapping consumer perceptions of creaminess and liking for liquid dairy products. Food Quality and Preference, 11, 239-246.

Rolls, B. J., Rolls, E. T., Rowe, E. A., \& Sweeney, K. (1981). Sensory specific satiety in man. Physiology and Behavior, 27, 137-142.

Rolls, E. T., Critchley, H. D., Browning, A. S., Hernadi, I., \& Lenard, L. (1999). Responses to the sensory properties of fat of neurons in the primate orbitofrontal cortex. Journal of Neuroscience, 19, 1532-40. 
Rolls, E. T. (2004). Multisensory Neuronal Convergence of Taste, Somatosensory, Visual, Olfactory, and Auditory inputs. In G.A.Calvert, C.Spence, \& B.E.Stein (Eds.), The handbook of multisensory processes (pp. 311-331). Cambridge, MA, USA: MIT Press.

Rolls, E. T. (2005). Taste, olfactory, and food texture processing in the brain, and the control of food intake. Physiology and Behavior, 85, 45-56.

Rolls, E. T., Verhagen, J. V., \& Kadohisa, M. (2003). Representations of the texture of food in the primate orbitofrontal cortex: neurons responding to viscosity, grittiness, and capsaicin. Journal of Neurophysiology, 90, 3711-3724.

Saint-Eve, A., Paci Kora, E., \& Martin, N. (2004). Impact of the olfactory quality and chemical complexity of the flavouring agent on the texture of low fat stirred yogurts assessed by three different sensory methodologies. Food Quality and Preference, 15, 655-668.

Shama, F. \& Sherman, P. (1973). Identification of stimuli controlling the sensory evaluation of viscosity. II. Oral methods. Journal of Texture Studies, 4, 111-118.

Szczesniak, A. S. (2002). Texture is a sensory property. Food Quality and Preference, 13, 215-225.

Todrank, J. \& Bartoshuk, L. M. (1991). A taste illusion: Taste sensation localized by touch. Physiology and Behavior, 50, 1027-1031.

Tolstoguzov, V. (2003). Some thermodynamic considerations in food formulation. Food Hydrocolloids, 17, 1-23.

Tuorila, H., Cardello, A. V., \& Lesher, L. (1994). Antecedents and consequences of expectations related to fat-free and regular-fat food. Appetite, 23, 247-264. 
Verhagen, J. V., \& Engelen, L. (2006). The neurocognitive bases of human multimodal food perception: Sensory integration. Neuroscience and Biobehavioral Reviews, 30, 613-650.

Ward, C. D. W., Koeferli, C. S., Schwegler, P. P., Schaeppi, D., \& Plemmons, L. E. (1999). European strawberry yogurt market analysis with a case study on acceptance drivers for children in Spain using principal component analysis and partial least squares regression. Food Quality and Preference, 10, 387-400.

Weenen, H., Jellema, R. H., \& de Wijk, R. A. (2005). Sensory sub-attributes of creamy mouthfeel in commercial mayonnaises, custard desserts and sauces. Food Quality and Preference, 16, $163-170$.

Wilkinson, C., Dijksterhuis, G. B., \& Minekus, M. (2000). From food structure to texture. Trends in Food Science \& Technology, 11, 442-450.

Wood, F. W. (1974). Approach to understanding creaminess. Starke, 26, 127-130. 
Table 1: Applied sensory descriptors used in the different experiments, special evaluation procedures and reference materials. Only descriptors significantly different between products are shown

\begin{tabular}{|c|c|c|c|c|c|c|}
\hline \multirow[t]{2}{*}{ Descriptors } & \multirow{2}{*}{ Special procedures during evaluation (reference material) } & \multirow{2}{*}{ Original Danish words } & \multicolumn{4}{|c|}{ Product } \\
\hline & & & $\begin{array}{l}\text { Acidified } \\
\text { milk drink }\end{array}$ & $\begin{array}{l}\text { Vanilla } \\
\text { yoghurt }\end{array}$ & $\begin{array}{c}\text { Plain } \\
\text { yoghurt }\end{array}$ & $\begin{array}{l}\text { Cream } \\
\text { Cheese }\end{array}$ \\
\hline Appearance & & Udseende & & & & \\
\hline $\begin{array}{l}\text { Visual } \\
\text { Viscosity }\end{array}$ & Measured during swirling of glass & Viskositet & $\sqrt{ }$ & & & \\
\hline Transparency & $\begin{array}{l}\text { Transparency of the sample at the edge of the glass tilted } \\
\text { approximately } 45^{\circ}\end{array}$ & Gennemsigtighed & $\sqrt{ }$ & & & \\
\hline $\begin{array}{l}\text { Glass Coating } \\
\text { Grainy }\end{array}$ & Amount of milk drink coating glass after swirling glass thoroughly & $\begin{array}{l}\text { Glasvedhæng } \\
\text { Grynethed }\end{array}$ & $\sqrt{ }$ & $\sqrt{ }$ & $\sqrt{ }$ & \\
\hline Grain size & & Størrelse af gryn & & & & $\sqrt{ }$ \\
\hline Glossy & & Blankhed & & & $\sqrt{ }$ & $\sqrt{ }$ \\
\hline White & & Hvid farve & & $\sqrt{ }$ & $\sqrt{ }$ & $\sqrt{ }$ \\
\hline Grey & & Grå farve & & & $\sqrt{ }$ & $\sqrt{ }$ \\
\hline Green & & Grøn farve & & & $\sqrt{ }$ & \\
\hline Yellow & & Gul farve & & $\sqrt{ }$ & $\sqrt{ }$ & $\sqrt{ }$ \\
\hline Blue & & Blå farve & & & & $\sqrt{ }$ \\
\hline Colour & & Farve & $\sqrt{ }$ & & & \\
\hline \multicolumn{2}{|c|}{ Aroma (evaluated by sniffing through the nose without sample in mouth) } & Lugt & & & & \\
\hline Buttermilk & (Organically produced buttermilk (ArlaFoods, Denmark)) & Kærnemælkslugt & $\sqrt{ }$ & & $\sqrt{ }$ & \\
\hline Cream & $\begin{array}{l}\text { (full fat homogenised milk ( } 3.5 \% \text { fat) and cream ( } 38 \% \text { fat) in a } 1 \\
\text { to } 5 \text { mixture) }\end{array}$ & Flødelugt & & & $\sqrt{ }$ & $\sqrt{ }$ \\
\hline Butter & $\begin{array}{l}\text { (Lump of organically produced old fashioned churned, salted } \\
\text { butter (Lurpak } \AA \text {, ArlaFoods, Denmark)) }\end{array}$ & Smørlugt & & & & $\sqrt{ }$ \\
\hline Lamb & (see below for detailed procedure ${ }^{\star}$ ) & Lammelugt & & & $\sqrt{ }$ & \\
\hline Goat & (goat yoghurt) & Gedelugt & & & & $\sqrt{ }$ \\
\hline Acidic & Intensity of acidic smell when first opening the sample & Syrlig lugt & & & & $\sqrt{ }$ \\
\hline Flour & $\begin{array}{l}\text { ( } 0.3 \mathrm{~L} \text { yoghurt (Jersey } 0.1 \% \text { fat, Thise Dairy, Denmark) added } 15 \\
\mathrm{~mL} \text { wheat flour) }\end{array}$ & Melet lugt & & & $\sqrt{ }$ & \\
\hline Raspberry & ( $0.5 \mathrm{~L} 0.5 \%$ fat milk added $30 \mathrm{ml}$ organically produced raspberry & Hindbrælugt & $\sqrt{ }$ & & & \\
\hline
\end{tabular}


cordial mixer)

\section{Flavour (evaluated with sample in mouth)}

\section{Buttermilk}

flavour

Cream flavour

Butter flavour

Lamb flavour

Goat flavour

Boiled milk

(see above)

(see above)

(Lump of organically produced old fashioned churned, salted

butter (Lurpak $\circledR$, ArlaFoods, Denmark))

(see above)

(see above)

( $0.5 \mathrm{~L} 3.5 \%$ fat milk $+1 / 2$ Malaco caramel roll $+100 \mathrm{~g}$ parsnip

boiled until caramel roll is melted and parsnip is soft. Sieved and cooled)

Flour flavour (see above)

Raspberry (see above)

Citrus flavour (A small piece of lemon)

Vanilla

Caramel

Coconut

(Werther's Original hard candy)

(coconut flavour, Weightwatchers)

(3.5\% fat plain yoghurt)

Taste

Sour taste

Sweet taste

Salt taste

\section{Texture and mouthfee}

Smoothness

Viscosity

Firmness

Chalkiness

Graininess

Stickiness

Meltdown rate

Meltdown rate

Amount of "work" to break down the bolus

Intensity of saliva losing lubrication in the mouth - using the

tongue against the palate or the back of the incisors

Fatty after

mouthfee

Dry after

mouthfeel
Degree of "fatty" mouth coating after expectoration of the sample

Degree of mouth dryness after expectoration of the sample

\section{Smag}

Smag af kærnemælk

Smag af fløde

Smag af smør

Smag af lam

Smag af ged

Melet smag

Hindbærsmag

Citrussmag

Vanille

Karame

Kokos

Yoghurt

Smag

Sur smag

Sød smag

Salt smag

Tekstur

Glathed

Viskositet

Fasthed

Kridtethed

Grynethed

Nedsmeltning

Astringerende

Fedtet eftermundfylde

Tør eftermundfylde 
Non-oral manipulation

Resistance Resistance during spread with a knife

Resistance Resistance during sucking through a straw

Non-oral

Rate of a spoonful to blur when it is placed on top of the sample

Graininess on

Half a spoon of sample spread on a lid

Viscosity with

spoon

Flow from

Viscosity measured after three stirs with spoon

spoon

Meta-descriptor

Creaminess Perceived creaminess of the sample evaluated in the mouth
Manipulation med ske

Modstand

Modstand

Gelstivhed

Grynethed på låg

Viskositet med ske

Sammenhængende flydning

fra ske

Metadeskriptor

Cremethed $\checkmark$

$\checkmark$ 
Table 2. Outline of differences between the sensory work of Kokini et al. (1987) and the present work.

\begin{tabular}{lll}
\hline Parameter & Kokini et al. & Our approach \\
\hline $\begin{array}{l}\text { Sensory methodology } \\
\text { Sensory vocabulary used }\end{array}$ & $\begin{array}{l}\text { Magnitude estimation } \\
\text { Fixed vocabulary previously } \\
\text { generated from most used } \\
\text { terms mentioned individually } \\
\text { by panellists, only for texture } \\
\text { properties }\end{array}$ & $\begin{array}{l}\text { Descriptive analysis } \\
\text { Vocabulary specific to range of product studied, generated by } \\
\text { consensus in panel for all sensory modalities - except for } \\
\text { creaminess, where idiosyncratic definitions was allowed }\end{array}$ \\
& Untrained panellists & $\begin{array}{l}\text { Panellists selected and trained according to ISO standards (ISO- } \\
\text { 8586-1, 1993) }\end{array}$ \\
Panellists & Room temperature & $\begin{array}{l}\text { Temperature in accordance with IDF Standard (IDF, 1997) } \\
\text { Conditions of test }\end{array}$ \\
Data analysis & Univariate data analysis & Multivariate data analysis
\end{tabular}


784 Table 3. Correlation coefficients between individual sensory properties and creaminess. Based on raw data, without averaging over panellists 785

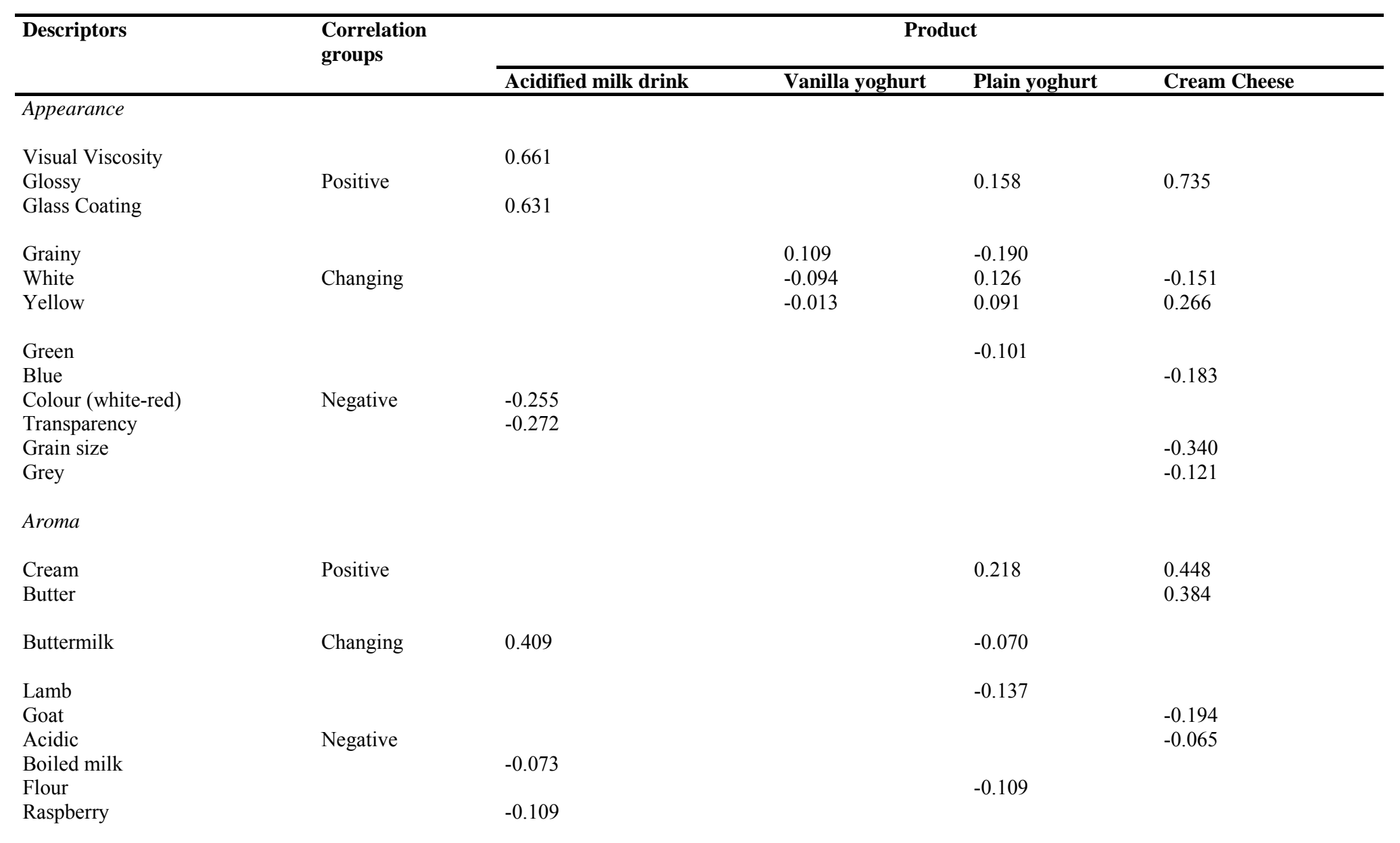

Flavour 
Cream flavour

Butter flavour

Vanilla

Caramel

Coconut
Citrus flavour

Buttermilk flavour

Flour flavour

Lamb flavour

Raspberry

Goat flavour

Boiled milk

Yoghurt

\section{Taste}

Sour taste

Salt taste

Sweet taste

Changing

$-0.336$

Texture and mouthfeel

Smoothness

Viscosity

Resistance

Fatty after mouthfeel

Meltdown rate

Astringent

\section{Chalkiness}

Firmness

Stickiness

Graininess

Dry after mouthfeel

Positive

0.145

0.570

0.414

$-0.034$

$-0.186$

0.238

0.803

0.781

Positive

0.599

Changing

0.378

Negative
0.103

0.203

0.222

$-0.074$

$-0.013$

$-0.261$

$-0.164$

$-0.496$

$-0.102$

$-0.224$

$-0.391$

$-0.233$

$-0.183$

0.178

0.313

0.194

0.303

0.311

0.287

0.469

0.238

0.484

0.361

$-0.059$

$-0.270$

0.140

$-0.277$

0.684

$-0.475$

$-0.582$

$-0.622$

$-0.629$

-0.814
-0.164

$-0.222$

$-0.309$

$-0.164$ 
Non-oral manipulation

Non-oral viscosity

Viscosity with spoon

Positive

Negative

Graininess on lid

Resistance to spread

Details about data

510 samples:

17 products

10 sensory panellists

3 sensory replicates
0.159

0.133

$-0.176$

$-0.662$

270 samples: $\quad 980$ samples: $\quad 600$ samples:

9 products 28 products 20 products

10 sensory $\quad 12$ sensory $\quad 10$ sensory panellists

panellists panellists 3 sensory replicates

3 sensory replicates 3 true replicates 
Fig. 1. Relationships between "Smoothness" and "Creaminess", specified for high (8.5\%) and low (2.0\%) milk solids non-fat (MNSF) level groups of samples. Sample abbreviations refer to MSNF-level $(8=8.5 \%, 2=2 \%)$; acidification method (lac, lactic acid bacteria $-\mathrm{a}$ drinking yoghurt, cit, citric acid - a milk-juice drink. Last 2-4 characters refer to added CMC 793 and pectin at different levels. For all details refer to (Janhøj et al., 2006b). 


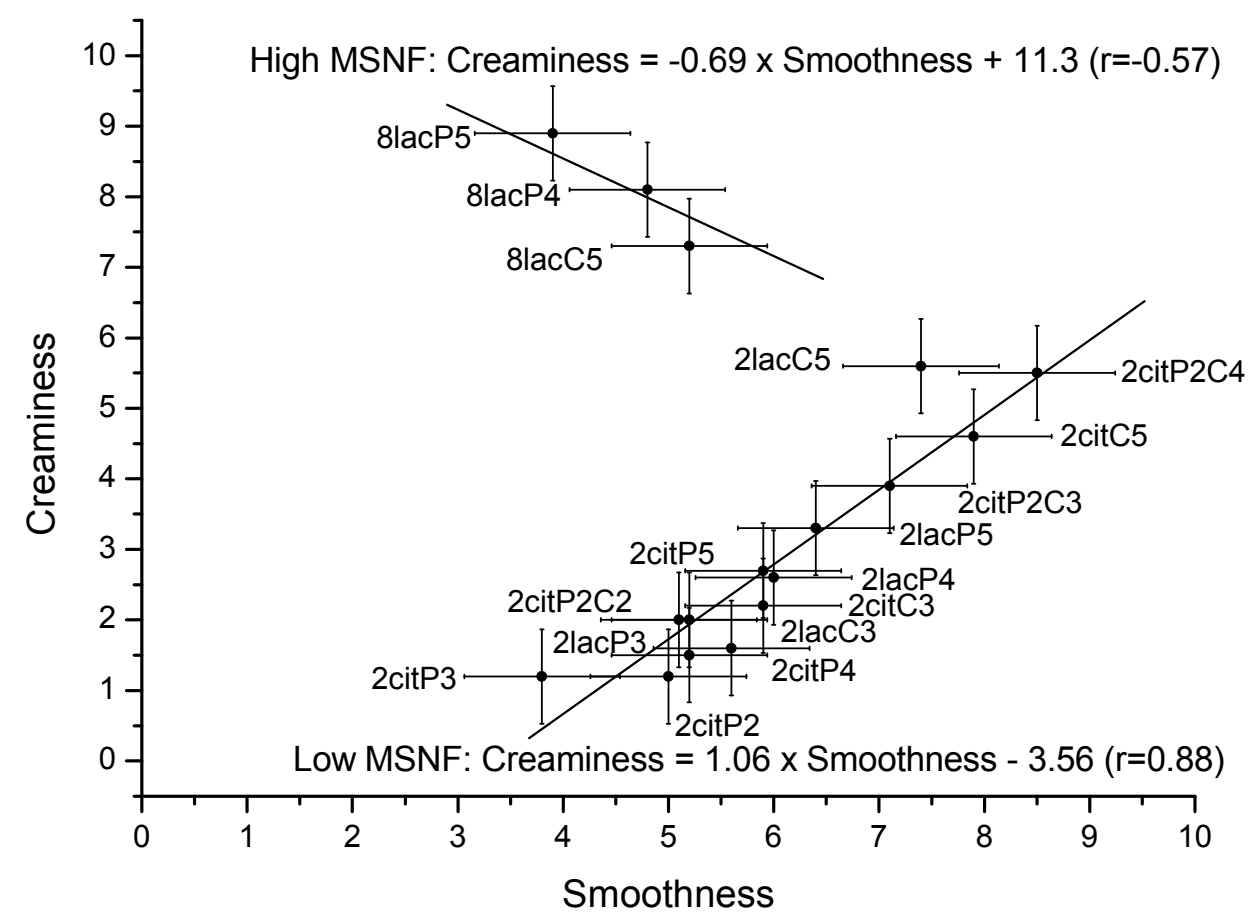

